\title{
Increasing Trend of Overweight and Obesity in a Rural Community in South East Nigeria
}

\author{
Uchenna N. Ijoma1,2, Paschal 0. Njoku², Ejikeme B. Arodiwe ${ }^{1,2}$, Chinwuba K. Ijoma ${ }^{1,2^{*}}$ \\ ${ }^{1}$ Department of Medicine, College of Medicine, University of Nigeria, Ituku/Ozalla Campus, Enugu, Nigeria \\ ${ }^{2}$ Department of Medicine, University of Nigeria Teaching Hospital, Ituku/Ozalla, Enugu, Nigeria \\ Email: *chinwuba.ijoma@unn.edu.ng
}

How to cite this paper: Ijoma, U.N., Njoku, P.O., Arodiwe, E.B. and Ijoma, C.K. (2020) Increasing Trend of Overweight and Obesity in a Rural Community in South East Nigeria. Open Journal of Epidemiology, 10, 323-333.

https://doi.org/10.4236/ojepi.2020.103026

Received: July 21, 2020

Accepted: August 24, 2020

Published: August 27, 2020

Copyright $\odot 2020$ by author(s) and Scientific Research Publishing Inc. This work is licensed under the Creative Commons Attribution International License (CC BY 4.0).

http://creativecommons.org/licenses/by/4.0/ (c) (i) Open Access

\begin{abstract}
Background: There is a global trend of increasing obesity, affecting mostly the high-and-middle income countries. Obesity was more prevalent in the urban areas but recent studies have suggested a disproportionate increase in obesity in the rural areas outstripping that of urban areas thus fueling the global obesity epidemic. This cross-sectional community study was undertaken to determine the prevalence of obesity in a rural community in South east Nigeria using Body Mass Index (BMI), waist circumference and waist-hip ratio. Materials and Methods: Adults ( $\geq 18$ years) in a rural community in Enugu State were studied in July 2019. The weight, height, waist circumference and hip circumference of the participants were taken. The BMI was calculated from the weight and height and the waist-hip ratio was determined for each participant. Results: A total of 210 participants were studied and analyzed. The prevalence of obesity and overweight by BMI was $10.9 \%$ and $28.0 \%$ respectively. There was no difference in the prevalence of obesity in males and females (10.9\% vs $10.9 \%$ ) and overweight (27\% for males and $28 \%$ for females). Significantly more females $(40 \%)$ than males $(7.3 \%)$ were obese by sex specific waist circumference $(p<0.001)$. There was no difference in the proportions of males $(49 \%)$ and females $(53.3 \%)$ that were obese by sex specific waist/hip ratio, $P$-Value 0.575 . There was no difference in the BMI between the age groups for males $(p=0.629)$ and females $(p=0.439)$. However, middle aged females ( 40 - 59 years) had higher waist circumference than the younger and older females $(p=0.025)$, while the older males (60 - 79 years) had higher waist-hip ratio than younger age groups $p=0.002$. Conclusions: The result of this study shows an increasing trend of obesity and overweight in a farming rural community in South east Nigeria compared with the prevalence recorded in the region in the past.
\end{abstract}

\section{Keywords}

Obesity, Rural Community, Nigeria, Body Mass Index 


\section{Introduction}

Obesity has become a global health concern. The latest figures from the World Health Organization (WHO) updated in March 2020 [1] showed that worldwide obesity has nearly tripled since 1975. In 2016, 650 million (13\%) and 1.9 billion (39\%) of the world adult population were obese and overweight respectively. It has been projected that many European countries will have an obesity prevalence of $20 \%$ to $43 \%$ by 2025 [2] and that by $2030,51 \%$ of the American population will be obese [3].

The national prevalence of overweight and obesity in some African countries ranges from $16.75 \%$ to $26 \%$ for overweight and $8 \%$ to $17 \%$ for obesity: in Ghana [4] the national prevalence of overweight and obesity is $25.4 \%$ and $17.1 \%$ respectively and $26.0 \%$ and $15.1 \%$ respectively in Cameroon [5]. In Nigeria, Chukwuonye et al. [6] undertook a systematic review of four articles published from January 2001 to September 2012 on the prevalence of overweight and obesity in adult Nigerians and found that the prevalence of overweight ranged from 20.3\% to $35.1 \%$, while the prevalence of obesity ranged from $8.1 \%$ to $22.2 \%$. However, more recently, the national prevalence of obesity in adults in 2016 was estimated at $8.9 \%$ according to the world factbook by CIA [7]. The figures for overweight and obesity from different parts of the country differ and are: $20.9 \%$ and $10.9 \%$ for Delta State in South south Nigeria [8], 20.3\% and 12.5\% for Ile-Ife in South west Nigeria [9]. In South east Nigeria, the prevalence of overweight and obesity in some selected urban areas was $29.4 \%$ and $19.5 \%$ respectively [10]. Obesity contributes to the global burden of chronic disease and disability and has been linked to a number of health complications including cardiovascular diseases (hypertension and stroke), respiratory disease, type 2 diabetes, some cancers (liver, colon, gall bladder, breast, ovarian, endometrial, prostate, kidney) [11].

Body mass index (BMI) is typically used to define overweight and obesity in epidemiological studies. Obesity is defined by the World Health Organization as Body Mass Index (BMI) greater than or equal to $30.0 \mathrm{Kg} \backslash \mathrm{m}^{2}$ in an adult [12]. BMI has low sensitivity and there is a large inter-individual variability in the percentage body fat for any given BMI value, partly attributed to age, sex, and ethnicity. Other methods for assessing the amount of fat in the body include waist circumference, and waist/hip ratio.

A recent report [13] has noted that contrary to the dominant paradigm, more than 55\% of the global rise in mean BMI from 1985 to 2017 was due to increases in BMI in rural areas with the exception of women in sub-Saharan Africa.

There is paucity of data on the prevalence of obesity in the rural community in South east Nigeria. Nonetheless, the few studies of obesity in rural communities in South east Nigeria had documented prevalence of obesity and overweight of $6.0 \%$ to $6.6 \%$ and about $9.8 \%$ respectively between 2011 and 2015 [14] [15].

This study was undertaken to determine the prevalence of overweight and obesity in a predominantly agricultural rural community in South east Nigeria using BMI, waist circumference and waist-hip ratio and to correlate BMI with 
waist circumference and waist-hip ratio. The study related the findings to previous documented prevalence of obesity and overweight in the zone.

\section{Materials and Methods}

\section{Study design}

This was a cross-sectional study of individuals living and working in a rural community in Enugu State, South east, Nigeria.

\section{Study site}

The study was conducted in Oduma, a rural community in Enugu State, South east, Nigeria located at $6^{\circ} 5^{\prime} 36^{\prime \prime} \mathrm{N}$ and $7^{\circ} 37^{\prime} 22^{\prime \prime} E$. Aninri Local Government of Enugu State has five communities and has a population of 136,221 person according to the 2006 National population census of Nigeria [16]. Oduma is the largest of the five communities with an estimated population of 60,000 inhabitants and was chosen because it is a completely rural and largely agricultural community. The community is located about $48 \mathrm{~km}$ from Enugu, the capital city of Enugu State.

\section{Study period}

The study was undertaken in July 2019. There was a prior community engagement with the leadership of the community from $3^{\text {rd }}$ to $5^{\text {th }}$ July 2020 when the details of the study were discussed with the community leaders and consent to undertake the study in the community obtained. The actual study took place on 19 and 20 July 2020.

\section{Ethical approval}

Ethical approval for the study was obtained from the University of Nigeria Teaching Hospital Ethics Committee.

\section{Sample size}

Sample size was determined from sample size calculation for cross-sectional study/survey from the formula below [17]:

$$
\text { Sample size }=\frac{Z_{1-a / 2}^{2} P(1-P)}{d^{2}}
$$

$Z_{1-a / 2}^{2}$ is standard normal variant (at $5 \%$ type 1 error) $=1.96$,

$P$ is expected proportion in population based on previous study $=0.066$.

Chukwonye et al. in a previous study had determined the prevalence of obesity in rural communities in the zone at $6.6 \%$ [15],

$d$ is pression $=0.05 \%$.

The minimum sample size for the study is

$$
\frac{1.96^{2} \times 0.066(1-0.066)}{0.05^{2}}=94.72
$$

The minimum sample size for the study $=95$.

However, all the participants who satisfied the study criteria were recruited to increase the power of the study.

\section{Study population}


Voluntary response sampling method was adopted. All adults ( $\geq 18$ years) of both sexes were encouraged to participate. The individuals who presented themselves were studied. Exclusion criteria were age less than 18 years, visitors to the community and pregnant women. Informed consent was obtained from each participant after explanation of the study in the local language.

\section{Data collection}

A validated semi-structured questionnaire was administered to obtain information from respondents. Anthropometric measurements were taken by medically trained research personnel using the methods detailed in the WHO STEPwise Approach to Surveillance (STEPS) [18]. Weight, was measured in kilogram to one decimal place using a scientific weighing scale (Electronic weighing scale by Omron, Japan (Omron digital scale; Omron Healthcare Co Ltd Kyoto, Japan. Model HN-283-E)) with the participant wearing light clothing. Height was measured to the nearest centimeter in the erect position using a portable height/length measuring board and the participant standing erect without footwear or headgear.

Gender-specific waist circumference and waist-hip ratio were defined and classified using the WHO cut-off points viz. [19]:

Waist circumference $>94 \mathrm{~cm}$ for men and $>80 \mathrm{~cm}$ for women,

Waist-hip ratio $\geq 0.90 \mathrm{~cm}$ for men and $\geq 0.85$ for women.

The waist and hip circumferences were measured with an inelastic tape calibrated in centimeters. Waist circumference was measured to the nearest $0.1 \mathrm{~cm}$ at midpoint between the lower margin of the last palpable rib and the top of the iliac crest.

Hip circumference was measured to nearest $0.1 \mathrm{~cm}$ at the widest circumference of the buttocks.

Body-mass index was calculated by dividing the weight in $\mathrm{kg}$ by the square of the height in meters and categorized into BMI grades according to WHO classification [20] viz; underweight $\mathrm{BMI}<18.5 \mathrm{~kg} / \mathrm{m}^{2}$, normal weight $18.5-24.9$ $\mathrm{kg} / \mathrm{m}^{2}$, overweight $25.0-29.9 \mathrm{~kg} / \mathrm{m}^{2}$, obesity $30.0-39.9 \mathrm{~kg} / \mathrm{m}^{2}$ and morbid obesity $\geq 40.0 \mathrm{~kg} / \mathrm{m}^{2}$.

\section{Statistical analysis}

Data were analyzed using IBM Statistical Package for Social Sciences SPSS version 21 (IBM Corp., Amonk, NY). Comparison of means between two groups and multiple groups was done with Student's t-test, analysis of variance (ANOVA) and cross tabulation as appropriate. Chi-square analysis was used for test of association while correlation between continuous variables was determined using Pearson's correlation. Statistical significance was set at $P$-Value $<$ 0.05 .

\section{Results}

\section{Socio-demographic characteristics of the study population}

Two hundred and ten participants (55 males and 155 females, M:F ratio 1:2.8) took part in the study and the data analyzed. The males were older than the fe- 
males (mean age: male $57.25 \pm 14.21$ years, female $49.10 \pm 16.6$ years, $P$-Value $0.001)$ and had higher mean weight $(60.60 \pm 10.85 \mathrm{~kg}$ vs $58.10 \pm 11.81 \mathrm{~kg}$; $P$-Value 0.003$)$ and taller, mean height $(160.75 \pm 9.37 \mathrm{~cm}$ vs $154.97 \pm 7.67 \mathrm{~cm}$; $P$-Values $<0.001)$ than the females (Table 1$)$. There were more people in the middle age bracket (40 - 59 years) than in the young bracket (20 - 39 years) and the elderly (60 - 79 years). The participants were evenly distributed between the sexes $(P$-Value $>0.05)$ with respect to age brackets, Table 2 .

Prevalence and pattern of obesity and overweight by different parameters

Overall, $10.9 \%$ and $28.0 \%$ of the participants were obese and overweight respectively by BMI. The prevalence of obesity and overweight was similar in males and females ( $10.9 \%$ vs $10.9 \%)$ and (27\% vs $28 \%)$ respectively. Majority of the study population ( $62 \%$ males and $50 \%$ females) were in the normal weight category of BMI $18.5-24.9 \mathrm{~kg} / \mathrm{m}^{2}$. Ten percent of the females were under-weight with $\mathrm{BMI}<18.5 \mathrm{~kg} / \mathrm{m}^{2}$ while none of the males was underweight. There was no statistical difference between the males and the females with respect to BMI categorization $(P$-Value 0.082$)$. The details of the BMI distribution are shown in Table 3.

Assessing obesity by waist circumference, significantly more females (62/155 [40\%]) had abnormally high sex-specific waist circumference than males (4/55 [7.3\%]) $p<0.001$, Table 3. Using waist/hip ratio as a measure of obesity, similar proportions of males (49\%) and females (53.5\%) were obese ( $P$-Value 0.575$)$.

Prevalence of obesity by Body Mass Index and central obesity in relation to age group and gender

There was no significant difference between the prevalence of obesity by BMI with respect to age groups for the males $(p=0.629)$ as well as for the females $(p$ $=0.439$ ), Table 4 . However, for central obesity by waist circumference, there was significant difference between the age groups for the females with the middle age ( 40 - 59 years) accounting for the majority $p=0.025$. There was no difference in the prevalence of central obesity by waist circumference with respect to age group for the males, $p=0.767$. Central obesity assessed by waist-hip ratio, was predominant in the elderly (age group 60 - 79 years) for the males $p=0.002$. This was not observed in the females $p=0.129$, Table 4 .

Relationship between body mass index, waist circumference and waist/hip ratio

Table 1. Demographic characteristics of the study population.

\begin{tabular}{|c|c|c|c|c|}
\hline Parameter & $\begin{array}{c}\text { Total } \\
\mathrm{N}=210\end{array}$ & $\begin{array}{c}\text { Male } \\
\mathrm{N}=55\end{array}$ & $\begin{array}{c}\text { Female } \\
\mathrm{N}=155\end{array}$ & $P$-Value \\
\hline Mean age (years $\pm S D$ ). & $51.24 \pm 16.24$ & $57.25 \pm 14.21$ & $49.10 \pm 16.6$ & 0.001 \\
\hline Mean weight (kg) & $59.54 \pm 11.79$ & $63.60 \pm 10.86$ & $58.10 \pm 11.81$ & 0.003 \\
\hline Mean height (cm) & $156.48 \pm 8.51$ & $160.75 \pm 9.37$ & $154.97 \pm 7.67$ & $<0.001$ \\
\hline Mean BMI $\left(\mathrm{kg} / \mathrm{m}^{2}\right)$ & $24.30 \pm 4.47$ & $24.60 \pm 3.69$ & $24.19 \pm 4.72$ & 0.563 \\
\hline Mean waist circumference $(\mathrm{cm})$ & $80.67 \pm 9.41$ & $81.80 \pm 8.48$ & $80.27 \pm 9.71$ & 0.302 \\
\hline Mean waist-hip ratio & $0.87 \pm 0.54$ & $0.89 \pm 0.50$ & $0.85 \pm 0.51$ & $<0.001$ \\
\hline
\end{tabular}


Table 2. Age stratification of the study population.

\begin{tabular}{ccccc}
\hline Age Stratification & Total & Male & Female & $P$-Value \\
\hline 20 - 39 Years. (Number) & $(50)$ & $(6)$ & $(44)$ & \\
Mean \pm SD & $29.32 \pm 6.58$ & $32 \pm 5.23$ & $28.84 \pm 6.5$ & 0.165 \\
& & & & \\
$\mathbf{4 0}$ - 59 Years. (Number) & 94 & 24 & 70 & \\
Mean \pm SD & $49.99 \pm 5.50$ & $50.44 \pm 5.46$ & $49.97 \pm 5.56$ & 0.957 \\
60 - 79 Years. (Number) & 66 & 25 & 41 & \\
Mean \pm SD & $69.62 \pm 5.96$ & $70.04 \pm 6.57$ & $69.37 \pm 5.60$ & 0.658 \\
\hline
\end{tabular}

Table 3. Parameters for obesity in the study population.

\begin{tabular}{|c|c|c|c|c|}
\hline Parameter & $\begin{array}{c}\text { Total } \\
\mathrm{N}=210 \\
\text { Number (\%) }\end{array}$ & $\begin{array}{c}\text { Male } \\
\mathrm{N}=55 \\
\text { Number (\%) }\end{array}$ & $\begin{array}{c}\text { Female } \\
\mathrm{N}=155 \\
\text { Number (\%) }\end{array}$ & $P$-Value \\
\hline \multicolumn{5}{|l|}{ BMI $\left(\mathrm{Kg} / \mathrm{M}^{2}\right)$} \\
\hline Underweight $(\mathrm{BMI}<18.5)$ & $16(76.0 \%)$ & $0(0)$ & $16(10.0)$ & \multirow{4}{*}{0.082} \\
\hline Normal weight (BMI 18.5 - 24.9) & $112(53.0)$ & $34(62.0)$ & $78(50.0)$ & \\
\hline Overweight (BMI 25.0 - 29.9) & $59(28.0 \%)$ & $15(27.0)$ & $44(28.0)$ & \\
\hline Obesity (BMI 30 - 39.9) & $23(10.9)$ & $6(10.9)$ & $17(10.9)$ & \\
\hline \multicolumn{5}{|l|}{ Waist Circumference (Cm) } \\
\hline Normal $($ Male $<94$, Female $<80$ ) & $144(68.6)$ & $51(92.7)$ & $93(60)$ & \multirow{2}{*}{$<0.001$} \\
\hline High $($ Male > 94; Female > 80) & $66(31.4)$ & $4(7.3)$ & $62(40)$ & \\
\hline \multicolumn{5}{|l|}{ Waist-Hip Ratio } \\
\hline Normal $($ Male $<0.9 ;$ Female $<0.85)$ & $100(47.6)$ & $28(51.0)$ & $72(46.5)$ & \multirow{2}{*}{0.638} \\
\hline High Male $>0.9$; Female $>0.85$ ) & $110(52.4)$ & $27(49.0)$ & $83(53.5)$ & \\
\hline
\end{tabular}

BMI; Body Mass Index.

Table 4. Prevalence of obesity by Body Mass Index and central obesity in relation to age group and gender.

\begin{tabular}{|c|c|c|c|c|c|}
\hline \multirow[b]{2}{*}{ Characteristic } & \multicolumn{3}{|c|}{ Age (Years) } & \multirow[b]{2}{*}{$\begin{array}{c}\text { Total } \\
210\end{array}$} & \multirow[b]{2}{*}{$P$-Value } \\
\hline & $\begin{array}{c}20-39 \\
\text { Number }=50\end{array}$ & $\begin{array}{c}40-59 \\
\text { Number }=94\end{array}$ & $\begin{array}{c}60-79 \\
\text { Number }=66\end{array}$ & & \\
\hline \multicolumn{6}{|l|}{ Body Mass Index } \\
\hline Male & 0 & 4 & 2 & 6 & 0.629 \\
\hline Female & 4 & 8 & 5 & 17 & 0.439 \\
\hline \multicolumn{6}{|c|}{ Waist Circumference } \\
\hline Male & 0 & 2 & 2 & 4 & 0.767 \\
\hline Female & 12 & 36 & 14 & 62 & 0.025 \\
\hline \multicolumn{6}{|l|}{ Waist-Hip Ratio } \\
\hline Male & 0 & 9 & 18 & 27 & 0.002 \\
\hline Female & 18 & 40 & 25 & 83 & 0.129 \\
\hline
\end{tabular}

Both waist circumference and waist/hip ratio correlated with BMI $(P$-Value $<$ $0.001)$, Table 5. In linear regression analysis, both waist circumference and waist/hip ratio predicted the presence of obesity but waist circumference more than waist/hip ratio (Table 6).

Generally, obesity by BMI was $10.9 \%$ and it is the same value for both males and females. However, the prevalence of central obesity by waist circumference 
Table 5. Correlation of BMI and waist circumference and waist hip ratio.

\begin{tabular}{ccc}
\hline & Correlation Coefficient & $\boldsymbol{P}$-Value \\
\hline Waist Circumference & $0.749^{* *}$ & $<0.001$ \\
Waist/Hip Ratio & $0.245^{* *}$ & $<0.001$ \\
\hline
\end{tabular}

${ }^{* *}$ Correlation is significant at the 0.01 level (2-tailed). BMI: Body Mass Index.

Table 6. Linear regression analysis of BMI and waist circumference and waist hip ratio.

\begin{tabular}{ccccccc}
\hline \multirow{2}{*}{ Model } & \multicolumn{2}{c}{ Unstandardized Coefficients } & Standardized Coefficients & & \\
\cline { 2 - 4 } & $\mathrm{B}$ & Std. Error & Beta & & Sig. \\
\cline { 2 - 5 } (Constant) & 3.975 & 3.232 & & 1.230 & 0.220 \\
Waist circumference & 0.392 & 0.025 & 0.826 & 15.998 & $<0.001$ \\
Waist hip ratio & -13.067 & 4.263 & -0.158 & -3.066 & 0.002 \\
\hline
\end{tabular}

${ }^{a}$ Dependable Variable: BMI. BMI: Body Mass Index.

was much higher; being $31.4 \%$, for the total population studied. There was a difference between the sexes: $40 \%$ for females and $7.3 \%$ for males. Conversely majority (52.4\%) of the participants had central obesity by waist-hip ratio and the proportion was similar in both sexes; $49 \%$ for males and $53 \%$ for females.

\section{Discussion}

This study established a crude prevalence of obesity of $10.9 \%$ and overweight of $28 \%$ in a rural farming community in South east Nigeria. The prevalence of overweight and obesity in Nigeria has been documented in many studies and shows a definite pattern: the prevalence of overweight and obesity is higher in the urban areas than in the rural communities and female have higher prevalence of obesity than males. In Nigeria, the prevalence of overweight individuals ranged from $20.3 \%-35.1 \%$, while the prevalence of obesity ranged from $8.1 \%$ $22.2 \%[6]$.

In a study of 2156 consecutive adult patients aged 18 - 90 years attending a rural mission hospital in Imo state, South east Nigeria in 2008/2009 by Iloh et al., the prevalence of obesity was $6.0 \%$ [14]. Another study of the prevalence of overweight and obesity in Abia State, South east Nigeria in 2015 by Chukwuonye et al. involving 2928 participants, documented the overall prevalence of overweight and obesity of $28.2 \%$ and $12.3 \%$ respectively. In that study, 1588 participants were rural dwellers of which $9.8 \%$ and $6.6 \%$ respectively were overweight and obese [15]. Abia State and Enugu State are in the same geopolitical zone of Nigeria and populated by the same ethnic group with similar cultural and social habits. The finding of prevalence of overweight and obesity of $9.8 \%$ and $6.6 \%$ is considerably much lower than the finding in this study. This tends to support the hypothesis that there is increasing prevalence of overweight and obesity in the rural communities.

The situation in the neighboring Niger Delta of Nigeria is similar. In a study of obesity in 388 participants in a farming rural community in the Niger Delta 
region of Nigeria in 2016 by Alikor CA and Nwafor CE, the prevalence of obesity was $3.4 \%[21]$.

A cross-sectional study of three rural communities in Ile-Ife, South west Nigeria in 2014 involving 777 ( 385 men and 395 women) adult participants by Adebayo et al., recorded a crude prevalence of overweight and obesity of $20.8 \%$ and $8.4 \%$, respectively, and obesity increased with age and peaked in the 51- to 60-year age-group in men and women [22].

Sola et al. [23] in a study of overweight and obesity in urban and rural communities in Benue state, North central Nigeria, found that the prevalence of overweight and obesity was $22 \%$ and $4 \%$ respectively. Obesity and overweight were more prevalent in the urban than in the rural communities. Specifically, the prevalence of overweight and obesity respectively in the rural community was $19.6 \%$ and $4.2 \%$ compared with the urban community with prevalence of overweight and obesity of $24.0 \%$ and $3.7 \%$ respectively. About $40 \%$ and $30 \%$ of females in urban and rural settlement, respectively, were either overweight or obese. In that study, $10.3 \%$ of the population had increased gender specific waist circumference (WC $\geq 94 \mathrm{~cm}$ in men and $\geq 80 \mathrm{~cm}$ in women). The study recruited individuals aged 18 to 45 years. The rather young population in the study may affect the prevalence of overweight and obesity as it has been established by some community-based studies that both conditions increase with age peaking about 40 - 64 year age bracket in Nigeria [8] [22].

From this study, although central obesity by waist circumference occurred in $31.4 \%$ of the general population; this occurred mostly in females $(40.0 \%)$ than in males $(7.3 \%), P$-Value $<0.001$. These values are close to the findings by Ulasi $e t$ al. [24] in 2010 in a community-based study of hypertension and cardio-metabolic syndrome in semi-urban and rural communities in Nigeria which recorded prevalence of central obesity by waist circumference of $53.7 \%$ and $8.9 \%$ in rural women and men respectively.

The participants in this study were predominantly female; 155 comprising about $74 \%$ of the study population. This can be explained by rural-urban migration as many of the males have migrated to cities in search of better quality of life. This is a world-wide phenomenon and also affects Nigeria [25]. The voluntary response sampling method was used for this study and therefore recruited all participants who presented themselves and satisfied the study criteria.

\section{Limitation of the Study}

One of the limitations of the study is that this is a single community study and the results may not be representative of the zone. A multi-community study covering the entire South east geopolitical zone will be desirable. The voluntary response sampling method used for this study may not be entirely without bias. Participants voluntarily presented themselves for the study. Although some residents may have elected not to participate, it is expected that this will affect individuals across all weight categories. Also, a more robust population size will be more representative of the community. There was a preponderance of females in 
the study. This may have introduced gender bias, but this preponderance of females in rural communities had been noted by other investigators in the region [24] [26] [27]. Regardless of these limitations this study provides a crude prevalence of obesity and overweight in individuals in the community studied.

\section{Conclusion}

We conclude from this study that the prevalence of obesity and overweight of $10.9 \%$ and $28.0 \%$ respectively in a rural farming community in the South east of Nigeria is higher than the values in the rural communities in the zone recorded in previous studies, thus suggesting an increasing trend of obesity and overweight in rural communities in South east Nigeria. Furthermore, there was no difference in the prevalence of obesity and overweight between the males and the females but there was disparity in the prevalence of obesity as determined by BMI, waist circumference and waist-hip ratio between the males and the females in this study. Waist circumference appears to be a better predictor of obesity than waist/hip ratio.

\section{Author's Contributions}

IU and IC conceptualized and designed the study. All authors were involved in data collection, IU and IC were responsible for data analysis and the initial draft. All authors read and approved the final draft.

\section{Acknowledgements}

The authors acknowledge the cooperation of the community leaders and the study participants. The contribution of the medically trained research personnel who assisted in data collection is acknowledged.

\section{Conflicts of Interest}

The authors declare no conflicts of interest regarding the publication of this paper.

\section{References}

[1] WHO (2020) Obesity and Overweight Fact Sheet.

[2] Pineda, E., Sanchez-Romero, L.M., Brown, M., Jaccard, A., Jewell, J., Galea, G., Webber, L. and Breda, J. (2018) Forecasting Future Trends in Obesity across Europe: The Value of Improving Surveillance. Obesity Facts, 11, 360-371. https://doi.org/10.1159/000492115

[3] Finkelstein, E.A., Khavjou, O.A., Thompson, H., Trogdon, J.G., Pan, L., Sherry, B. and Dietz, W. (2012) Obesity and Severe Obesity Forecasts through 2030. American Journal of Preventive Medicine, 42, 563-570. https://doi.org/10.1016/j.amepre.2011.10.026

[4] Ofori-Asenso, R., Agyeman, A.A., Laar, A. and Boateng, D. (2016) Overweight and Obesity Epidemic in Ghana-A Systematic Review and Meta-Analysis. BMC Public Health, 16, Article No. 1239. https://doi.org/10.1186/s12889-016-3901-4 
[5] Nansseu, J.R., Noubiap, J.J. and Bigna, J.J. (2019) Epidemiology of Overweight and Obesity in Adults Living in Cameroon: A Systematic Review and Meta-Analysis. Obesity (Silver Spring), 27, 1682-1692. https://doi.org/10.1002/oby.22566

[6] Chukwuonye, I.I., Chuku, A., John, C., Ohagwu, K.A., Imoh, M.E., Isa, S.E., Ogah, O.S. and Oviasu, E. (2013) Prevalence of Overweight and Obesity in Adult Nigerians-A Systematic Review. Diabetes, Metabolic Syndrome and Obesity: Targets and Therapy, 6, 43-47. https://doi.org/10.2147/DMSO.S38626

[7] Central Intelligence Agency. Obesity, Adult Prevalence Rate. http://www.cia.gov $>$ publications $>$ the-world-factbook $>$ fields

[8] Umuerri, E.M., Ayandele, C.O. and Eze, G.U. (2017) Prevalence and Sociodemographic Correlates of Obesity and Overweight in a Rural and Urban Community of Delta State, Nigeria. Sahel Medical Journal, 20, 173-178.

https://doi.org/10.4103/1118-8561.230258

[9] Adedoyin, R.A., Mbada, C.E., Balogun, M.O., Adebayo, R.A., Martins, T. and Ismail, S. (2009) Obesity Prevalence in Adult Residents of Ile-Ife, Nigeria. Nigerian Quarterly Journal of Hospital Medicine, 19, 100-105.

https://doi.org/10.4314/nqjhm.v19i1.50211

[10] Ijoma, U., Chime, P., Onyekonwu, C., Ezeala-Adikaibe, B., Orjioke, C., Anyim, O., Onodugo, O., Aneke, E., Nwatu, C., Young, E., Mbadiwe, N., Ekenze, O., Okoye, J., Abonyi, M., Ulasi, I., Mbah, A. and Onodugo, P. (2019) Factors Associated with Overweight and Obesity in an Urban Area of South East Nigeria. Food and Nutrition Sciences, 10, 735-749. https://doi.org/10.4236/fns.2019.107054

[11] Kinlen, D., Cody, D. and O'Shea, D. (2018) Complications of Obesity, QJM: An International Journal of Medicine, 111, 437-443.

https://doi.org/10.1093/qjmed/hcx152

[12] World Health Organization (1995) Technical Report Series. World Health Organization, Geneva, Physical Status: The Use and Interpretation of Anthropometry. 854: 1-1-9950.

[13] Bixby, H., Bentham, J., Zhou, B., et al. (2019) Rising Rural Body-Mass Index Is the Main Driver of the Global Obesity Epidemic in Adults. Nature, 569, 260-264. https://doi.org/10.1038/s41586-019-1171-x

[14] Iloh, G., Amadi, A.N., Nwankwo, B.O. and Ugwu, V.C. (2011) Obesity in Adult Nigerians: A Study of Its Pattern and Common Primary Co-Morbidities in a Rural Mission General Hospital in Imo State, South-Eastern Nigeria. Nigerian Journal of Clinical Practice, 14, 212-218. https://doi.org/10.4103/1119-3077.84019

[15] Chukwuonye, I.I., Chuku, A., Onyeonoro, U., Ukegbu, A., Anyabolu, E., et al. (2015) Body Mass Index, Prevalence and Predictors of Obesity in Urban and Rural Communities in Abia State South Eastern Nigeria. Journal of Diabetes and Metabolism, 6, 570. https://doi.org/10.4172/2155-6156.1000570

[16] 2006 Population and Housing Census, Priority Table IV. National Population Commission, Nigeria. http://www.population.gov.ng

[17] Charan, J. and Biswas, T. (2013) How to Calculate Sample Size for Different Study Designs in Medical Research. Indian Journal of Psychological Medicine, 35, 121-126. https://doi.org/10.4103/0253-7176.116232

[18] WHO STEPwise Approach to Surveillance-Instrument V3.2. https://www.who.int>ncds>steps

[19] Waist Circumference and Waist-Hip Ratio: Report of a WHO Expert Consultation, Geneva, 8-11 December 2008. https://www.who.int>obesity>who 
[20] WHO Consultation on Obesity (1999) Obesity: Preventing and Managing the Global Epidemic: Report of a WHO Consultation. WHO Technical Report Series 894. Geneva.

[21] Alikor, C.A. and Nwafor, C.E. (2016) The Prevalence and Predictors of Generalised Obesity in a Rural Farming Community in the Niger Delta Region of Nigeria. The Nigerian Health Journal, 16.

[22] Adebayo, R.A., Balogun, M.O., Adedoyin, R.A., Obashoro-John, O.A., Bisiriyu, L.A. and Abiodun, O.O. (2014) Prevalence and Pattern of Overweight and Obesity in Three Rural Communities in Southwest Nigeria. Diabetes, Metabolic Syndrome and Obesity: Targets and Therapy, 7, 153-158. https://doi.org/10.2147/DMSO.S55221

[23] Sola, A.O., Steven, A.O., Kayode, J.A. and Olayinka, A.O. (2011) Underweight, Overweight and Obesity in Adults Nigerians Living in Rural and Urban Communities of Benue State. Annals of African Medicine, 10, 139-143. https://doi.org/10.4103/1596-3519.82081

[24] Ulasi, I.I., Ijoma, C.K. and Onodugo, O.D. (2010) A Community-Based Study of Hypertension and Cardiometabolic Syndrome in Semi-Urban and Rural Communities in Nigeria. BMC Health Services Research, 10, Article No. 71. https://doi.org/10.1186/1472-6963-10-71

[25] Ehirim, N.C., Onyeneke, R.U., Chidiebere-Mark, N.M. and Nnabuihe, V.C. (2012) Effect and Prospect of Rural to Urban Migration on the Poverty Status of Migrants in Abia State, Nigeria. Agricultural Science Research Journal, 2, 145-153.

[26] Ulasi, I.I., Ijoma, C.K., Onodugo, O.D., Arodiwe, E.B., Ifebunandu, N.A. and Okoye, J.U. (2013) Towards Prevention of Chronic Kidney Disease in Nigeria: A Community-Based Study in Southeast Nigeria. Kidney International Supplements, 3, 195-201. https://doi.org/10.1038/kisup.2013.13

[27] Akpan, E.E., Ekrikpo, U.E., Udo, A.I.A. and Bassey, B.E. (2015) Prevalence of Hypertension in Akwa Ibom State, South-South Nigeria: Rural versus Urban Communities Study. International Journal of Hypertension, 2015, Article ID: 975819. https://doi.org/10.1155/2015/975819

\section{Appendix}

\section{Questionnaire}

The questionnaire was a simple one to capture the information sought and was designed by the authors and pretested in a small population of the community before use in the main study. The items in the questionnaire were:

1) Biodata: Study identification number, age of participant, gender of participant, occupation, educational attainment.

2) Anthropometry: Height, weight, waist circumference, hip circumference. 